Volume 8(3), 101-116. https://doi.org/10.18608/jla.2021.7184

\title{
Narrowing the Feedback Gap: Examining Student Engagement with Personalized and Actionable Feedback Messages
}

\author{
Hamideh Iraj ${ }^{1}$, Anthea Fudge ${ }^{2}$, Huda Khan ${ }^{3}$, Margaret Faulkner ${ }^{4}$, Abelardo Pardo ${ }^{5}$, Vitomir \\ Kovanović6
}

\begin{abstract}
One of the major factors affecting student learning is feedback. Although the importance of feedback has been recognized in educational institutions, dramatic changes-such as bigger class sizes and a more diverse student population-challenged the provision of effective feedback. In light of these changes, educators have increasingly been using new digital tools to provide student feedback, given the broader adoption and availability of these new technologies. However, despite these efforts, most educators have limited insight into the recipience of their feedback and wonder which students engage with feedback. This problem is referred to as the "feedback gap," which is the difference between the potential and actual use of feedback, preventing educators and instructional designers from understanding feedback recipience among students. In this study, a set of trackable call-to-action (CTA) links were embedded in feedback messages focused on learning processes and self-regulation of learning in one fully online marketing course and one blended bioscience course. These links helped us examine the association between feedback engagement and course success. We also conducted two focus groups with students from one of the courses to further examine student perceptions of feedback messages. Our results across both courses revealed that early engagement with feedback is positively associated with passing the course and that most students considered feedback messages helpful in their learning. Our study also found some interesting demographic differences between students regarding their engagement with the feedback messages. Such insight enables instructors to ask "why" questions, support students' learning, improve feedback processes, and narrow the gap between potential and actual use of feedback. The practical implications of our findings are further discussed.
\end{abstract}

\section{Notes for Practice}

- Calls to action (CTAs) in feedback messages offer a mechanism for capturing data on students' engagement with customized feedback messages.

- Student characteristics aid predictions on student engagement with technology-mediated feedback that contains a CTA.

- The emerging patterns could help instructors and educational designers narrow the feedback gap and improve feedback recipience.

\section{Keywords}

Feedback, learning analytics, higher education, feedback gap, data-driven approaches

Submitted: 07/05/2020 - Accepted: 13/04/2021 — Published: 05/11/2021

${ }^{1}$ Email: hamideh.iraj@mymail.unisa.edu.au Address: UniSA STEM, University of South Australia, City West Campus DP1-02, Mawson Lakes, SA 5095, Australia. ORCID ID: https://orcid.org/0000-0002-7831-9324

${ }^{2}$ Email: anthea.fudge@unisa.edu.au Address: Education Futures, University of South Australia, City West Campus DP2-42, Adelaide, SA 5000, Australia. ORCID ID: https://orcid.org/0000-0002-1737-7432

${ }^{3}$ Email: huda.khan@abdn.ac.uk Address: Business School, University of Aberdeen, 719 MacRobert Building, Aberdeen AB24 3FX, Scotland, United Kingdom. ORCID ID: https://orcid.org/0000-0002-4962-9526

${ }^{4}$ Email: margaret.faulkner@unisa.edu.au Address: UniSA Business, University of South Australia, City West Campus Y4-31, Adelaide, SA 5000, Australia. ORCID ID: https://orcid.org/0000-0002-6643-5600

${ }^{5}$ Email: abelardo.pardo@unisa.edu.au Address: UniSA STEM, University of South Australia, Mawson Lakes Campus MC2-19, Mawson Lakes, SA 5095, Australia. ORCID ID: https://orcid.org/0000-0002-6857-0582

Corresponding author ${ }^{6}$ Email: vitomir.kovanovic@unisa.edu.au Address: Centre for Change and Complexity in Learning, University of South Australia, City West Campus BH3-21, Adelaide, SA 5000, Australia. Email: vitomir.kovanovic@unisa.edu.au. ORCID ID:

https://orcid.org/0000-0001-9694-6033 


\section{Introduction}

There has been a continuous shift in higher education over the past decades toward massification and consumerization (Pardo, Jovanovic, Dawson, Gašević, \& Mirriahi, 2019). Universities are operating in a dynamic market with fierce competition for new students and other income sources (Evans, 2013); the associated reductions in government funding and calls for more efficient operations have led to larger class sizes in the name of profitability of operations (Boud \& Molloy, 2013b). However, larger classes are associated with a wide range of unfavourable outcomes, such as poor feedback (Gibbs \& Simpson, 2005), higher dissatisfaction (Gannaway, Green, \& Mertova, 2018), fewer opportunities for monitoring student learning progression (Hattie, 1999), and lower academic performance (Krueger, 1999).

While improving students' university experience is a complex and challenging problem, effective feedback plays a key role in this process. This finding is part of a large network of evidence emerging from numerous studies pointing to the power of feedback in education (Hattie \& Timperley, 2007). However, feedback is only effective if students take it up and act upon it (Winstone, Nash, Rowntree, \& Parker, 2017; Sutton, 2012). To do so, students need to understand the feedback, develop the capacity to judge their work, manage their emotions upon receiving feedback, and finally act upon the information they have been given (Carless \& Boud, 2018). This discrepancy between the potential and actual use of feedback has been referred to as the "feedback gap" (Dawson et al., 2018; Evans, 2013), and its evaluation is the key to understanding the effectiveness of the provided feedback on improving student learning.

Taking action requires a student capability termed proactive recipience of feedback (Winstone, Nash, Parker, \& Rowntree, 2017). A lack of research examining how students interact with and are transformed by computer-assisted or produced feedback (Iraj, Fudge, Faulkner, Pardo, \& Kovanović, 2020) limits the ability to build student capability and improve learning outcomes. Research on student feedback across institutions has shown that feedback that works for students encourages their active learning and, according to Molloy, Boud, and Henderson (2020), "called to action in some way" (p. 534). However, it remains unknown whether this also applies to online learning environments where technology is used to generate feedback. Calls to action (CTAs) have successfully been used in other fields, such as marketing, where data-driven evaluation of their effectiveness shows positive effects (Hartemo, 2016; Sahni, Wheeler, \& Chintagunta, 2018; Singh, Singh, \& Shriwastav, 2019; Zhang, Kumar, $\&$ Cosguner, 2017). An example is the use of online interventions to encourage social marketing health behaviour change, where messaging strategies often combine tailoring with personalization of messages and take advantage of the Internet's reach and cost-effectiveness to increase the scale of behavioural change achieved (Cugelman, Thelwall, \& Dawes, 2011). Research that examines whether the same approaches can work for educational feedback is needed to understand students' perception of feedback and its effectiveness at improving learning outcomes.

This paper aims to investigate student engagement with technology-mediated feedback that provides specific CTAs. Attention is focused on feedback operating at the task, process, and self-management levels, as conceptualized by Hattie and Timperley (2007, p. 87). We introduce a data-driven method from digital marketing and apply that method to educational feedback messages. Specifically, in this paper we focus on CTA links in feedback emails to explore the association between feedback engagement, student characteristics, and academic success. Both online and blended courses were chosen to take into account the impact of the learning environment on student engagement with feedback. The insights of the present study will help course instructors and designers develop feedback that scaffolds development of proactive recipience and ultimately improves student learning experience and success.

\section{Literature Review}

\subsection{Toward Actionable Educational Feedback}

Two main paradigms have dominated feedback research in education: the first one focused on the content of the feedback itself and the information it contains, the second on the action taken by teachers and the feedback recipients, students (Carless \& Boud, 2018). We will refer to these as information and action approaches, respectively. Earlier research was mainly undertaken in the context of the information paradigm. In their groundbreaking paper, Hattie and Timperley (2007, p. 81) define feedback as "information provided by an agent (e.g., teacher, peer, book, parent, self, experience) regarding aspects of one's performance or understanding." They differentiate among feed up (where am I going?), feed back (how am I going?), and feed forward (where to next?) and hold that addressing these questions in the design phase helps to provide feedback that is effective. In this way, good feedback shows the learner's process toward a learning goal based on specific standards and prior performance and points to the improvement scenarios (Hattie \& Timperley, 2007). Another aspect of feedback is the level of cognitive complexity. In one well-regarded example of this kind of work, Hattie and Timperley (2007) differentiate between (1) task-level feedback, (2) process-level feedback, (3) and self-regulatory feedback.

In task-level feedback, also known as confirmatory or disconfirmatory feedback, the goal is to provide feedback for a particular learning task; with process-level feedback, the focus shifts to specific learning strategies and learning processes 
required to complete the task; and at a self-regulatory level, the goal is to enable students to monitor and regulate their learning (Winne \& Hadwin, 1998; Butler \& Winne, 1995). This kind of feedback supports students to set or adjust their goals, manage their time and study environment, select appropriate learning strategies, and test the effectiveness of adopted study strategies (Winne \& Hadwin, 1998).

More recent research has focused on supporting students' and teachers' actions. This new paradigm shifts the focus to providing actionable feedback, where feedback not only is potentially useful information but also highlights opportunities for students to take action and supports the process of changing student behaviour (Carless \& Boud, 2018). This focus on student action is emphasized by Boud and Molloy (2013a, p. 205), who define feedback as "a process whereby learners obtain information about their work to appreciate the similarities and differences between the appropriate standards for any given work, and the qualities of the work itself, to generate improved work." Acting on feedback was also considered by Shute (2008, p. 153), who views feedback as "information communicated to the learner that is intended to modify his or her thinking or behaviour to improve learning."

The shift in the focus of feedback acknowledges the importance of developing student capabilities to facilitate understanding and taking action from feedback. It is supported by research showing that a lack of proactive behaviour from students in relation to seeking and using feedback requires additional support to develop a mindset of proactive recipience, where students take on an active rather than a passive role as the recipient of feedback (Winstone, Nash, Rowntree, \& Parker, 2017).

\subsection{Feedback Recipience and Actionability}

Feedback recipience deals specifically with how students understand, interpret, and act upon feedback (Howell, Roberts, \& Mancini, 2018). As indicated by Chong (2020), feedback recipience is always contextualized within broader sociocultural, instructional, and learning contexts and depends on students' abilities, beliefs, experience, and learning goals. Providing feedback without considering such factors is not necessarily sufficient for improving learning and student success (Hattie \& Timperley, 2007; Winstone, Nash, Parker, \& Rowntree, 2017; Winstone, Mathlin, \& Nash, 2019). Communicating feedback is the starting point of the feedback process, not its end point (Kluger \& DeNisi, 1996). Students need to understand the feedback, come up with plans to act on the feedback, and then improve the quality of their work. The development of such skills improves feedback recipience and is encapsulated in the concept known as feedback literacy (Carless \& Boud, 2018). Interpretation by students taps into a self-developmental aspect of feedback, which requires an openness to change of educational identity that may not be present in all learners (Sutton, 2012). Similarly, feedback requires the student to take some form of action to be effective; feedback without action is said to be equally unproductive (Winstone, Nash, Rowntree, \& Parker, 2017).

There is consensus in the education literature that feedback recipience is a complex, multi-dimensional, and contingent topic (Shute, 2008; Winstone, Nash, Parker, \& Rowntree, 2017). While feedback can enhance learning performance, this is not consistent for every context and all students (Evans, 2013; Hattie \& Timperley, 2007; Kluger \& DeNisi, 1996; Winstone, Nash, Parker, \& Rowntree, 2017). In some instances, feedback does not impact learning at all or may even hamper performance (Kluger \& DeNisi, 1996; Wisniewski, Zierer, \& Hattie, 2020) due to negative perceptions and confusion (Howell et al., 2018), especially in technology-mediated settings (Gašević, Dawson, \& Siemens, 2015). For example, student dashboards often compare students' performance with the class average. As a result, high-achieving students can mistakenly think that they are performing well when they are, in fact, underperforming against their past performance. This will reduce their likelihood of taking action (Gašević et al., 2015). However, in another study comparing feedback written on paper for students with technology-mediated feedback, technology overcame misunderstanding and interpretation from poor handwriting and offered the benefit of immediate action that encouraged students to engage with learning (Chong, 2019).

As a result of the inherent complexity and contingency of feedback on personal situations, the effectiveness of the process is increased when feedback is personalized (Pardo et al., 2019; Liu, Bartimote-Aufflick, Pardo, \& Bridgeman, 2017). For instance, digital traces of the student's engagement with online activities were used to personalize feedback automatically sent each week and were shown to have a positive effect on student satisfaction with feedback and academic performance (Pardo et al., 2019). Additionally, individual student differences affect learning success, so we need to consider their effect on feedback recipience (Bjork, Dunlosky, \& Kornell, 2013; Winstone, Nash, Parker, \& Rowntree, 2017). For example, highly developed self-regulated learning skills (Winne \& Hadwin, 1998) determine how students utilize feedback to alter their study approaches (Butler \& Winne, 1995). Finally, the perception of feedback is further influenced by learners' goal orientation and motivation (Senko, Hulleman, \& Harackiewicz, 2011), as well as demographic characteristics (Turner \& Gibbs, 2010) and study habits (Dawson et al., 2018).

\subsection{Technology-Mediated Feedback in Higher Education}

The significant changes to the higher education sector have made it much more challenging for instructors to monitor student progress and provide useful feedback to students (Boud \& Molloy, 2013b; Rowe, 2017; Rowe \& Wood, 2009; Nicol, 2010; Carless, 2020). To address some of these challenges, universities have increasingly turned to technology, with new technological 
advances offering the promise of scaling up and improving the usefulness of provided feedback (Dawson et al., 2018; Pardo et al., 2019). A rich source of information about students' learning processes is contained in educational databases and learning management systems (LMSs), waiting for educators and researchers to take advantage of the deluge of raw data to create actionable feedback that can help students in their learning process (Long \& Siemens, 2011; Pardo et al., 2019). Over time, different technology-supported feedback systems have been developed and implemented at universities across the world. Examples are Course Signals (Arnold \& Pistilli, 2012), E2Coach (McKay, Miller, \& Tritz, 2012), Competency Map (Grann \& Bushway, 2014), SRES (Liu et al., 2017), and OnTask (Lim et al., 2019; Pardo et al., 2018). Technology-supported feedback systems opened new opportunities for providing feedback to students and have proved to be effective for engaging students (Dawson et al., 2018; Lim et al., 2019), boosting students' satisfaction (Pardo et al., 2019), and improving outcomes (Dawson et al., 2018; Pardo et al., 2019). To be effective, these systems require a delicate combination of course design, instructors' domain knowledge, and automated processes for feedback provision at scale (Pardo et al., 2019), typically using email or SMS messages, or student dashboards.

\subsection{Actionability and Effectiveness of Technology-Mediated Feedback}

While the importance of feedback actionability is widely acknowledged in the literature (Molloy et al., 2020), there has been very limited empirical research on the effectiveness of technology-mediated feedback systems. Such systems have commonly been in the form of educational dashboards and email messages, which often lack guidance for students to interpret information and specific CTAs to promote active learning. Gašević and colleagues (2015) discuss how poorly designed systems promote ineffective learning strategies that do not contribute to students' overall learning success. This phenomenon was observed in Corrin and de Barba (2015), where students' inability to interpret their progress on educational dashboards resulted in confusion and subsequent inaction, with students unable to benefit from feedback. Early attempts to analyze students' actions on dashboards relied on self-reported surveys and interviews (Corrin \& de Barba, 2014; Winstone, 2019). Although these research methods can offer useful insight into students' actions, they are unscalable, and they cannot show patterns in more significant cohorts of students. To address some of the challenges of such systems, there have been calls for the use of evidence-based research to inform the design of learning analytics systems (Gašević et al., 2015).

While there are many ways to make technology-mediated feedback actionable (Winstone, Nash, Parker, \& Rowntree, 2017), one of the most straightforward approaches is to include direct hyperlinks to the recommended learning resources and activities. This practice was attempted by Herodotou, Heiser, and Rienties (2017), who used direct links to preparation materials in their feedback messages to encourage students to engage with the resources and improve their learning outcomes. A similar approach was adopted by Tempelaar, Rienties, Mittelmeier, and Nguyen (2018), who provided links to Khan Academy videos explaining relevant course concepts to help students find relevant information more easily. In a similar vein, the dashboard developed by Broos and colleagues (2017) included a button labelled "Okay, what now?", which suggested the next student activity - typically additional learning content. Although student-level differences affect students' engagement with feedback (Butler \& Winne, 1995; Hattie \& Timperley, 2007; Nicol \& Macfarlane-Dick, 2006; Winstone, Nash, Parker, \& Rowntree, 2017), and researchers agree that "one size does not fit all" when it comes to the provision of feedback (Teasley, 2017), this topic has not yet been investigated quantitatively in detail. This is mainly due to the difficulty of tracking students' activities and capturing their engagement with feedback messages. To the best of our knowledge, there is very little empirical evidence of the effectiveness of feedback that contains actionable links on students' learning experience and success. As a result of this gap in the research literature, two research questions remain unanswered: first, what is the effect of student engagement with feedback on academic performance, and, second, how does student engagement with feedback vary by student characteristics?

\subsection{Activity Tracking in Digital Marketing}

While tracking student engagement with feedback messages has not been widely used in education settings, the field of digital marketing has tracked customer activities for understanding communication effectiveness and boosting customer engagement. The systematic collection and examination of user engagement with email is a critical component of many digital marketing campaigns, necessary for assessing their effectiveness (Hartemo, 2016; Sahni et al., 2018; Singh et al., 2019; Zhang et al., 2017). A common approach for tracking prospect or customer behaviour in a marketing campaign is personalized email messages with a trackable CTA that can reveal how users engage with the content (Gunelius, 2018). CTAs specify actions for the individual to take as a next step. Direct mail and telemarketing have used telephone call centres and reply-paid postcards for decades to increase sales. With the rise of the Internet, marketers now have a greater reach that allows many cycles of action and reaction (Deighton \& Kornfeld, 2009).

The success of a marketing campaign is measured through a data-driven mechanism in which prospective customers click on CTAs and progressively engage with the buying process. A click on the CTA button redirects users to a specific page on the target website known as the landing page (Hanna, Swain, \& Smith, 2015), which is designed to encourage the viewer to engage with the next activity (e.g., buying an item, downloading a brochure, installing a demo version of the software) 
(Applegate, 2005; Parsons \& Lepkowska-White, 2010). The data-driven approach of tracking engagement with different marketing messages is used extensively in digital marketing, allowing marketers to design and analyze the campaign success quantitatively (Hanna et al., 2015). In this study, we propose a new method based on digital marketing techniques to investigate student engagement with feedback messages.

\section{Research Questions}

Feedback researchers agree that the goal of feedback is to support students to make decisions; it is clear that providing information alone as feedback is inadequate for learning (Winstone, Nash, Parker, \& Rowntree, 2017). Typical feedback systems stop at information transfer and ignore the processes required to turn feedback into actions (Carless \& Boud, 2018; Winstone, 2019), leading to the scarcity of behavioural data in education (Winstone, 2019). One problem in the feedback process has been a lack of any mechanism to track students' use of feedback (Dawson et al., 2018; Wong \& Li, 2018; Ryan, Gašević, \& Henderson, 2019; Ellis, 2013). The invisibility of students' engagement with feedback (Price, Handley, Millar, \& O'Donovan, 2010) and the inability to measure the effects of feedback prevent researchers and educators from delving deep into feedback as a nuanced and multifaceted phenomenon (Winstone, 2019) and from customizing the feedback at a deeper level. Consider this quotation attributed to John Wanamaker, a prominent figure in marketing: "Half the money I spend on advertising is wasted; the trouble is I don't know which half" (Glass \& Callahan, 2014, p. 18). The same holds true for education; educators typically invest a lot of time and effort in producing feedback for students (Winstone \& Nash, 2016, p. 6), yet they have little idea how students are engaging with that feedback; which students are reading their feedback; and which students are acting, or not acting, on the feedback (Kizilcec \& Brooks, 2017; Winstone, 2019). In this regard, a data-driven approach to capturing students' engagement with feedback presents tremendous opportunities to narrow the feedback gap by making feedback messages actionable. In this paper, we explore the actionability of personalized technology-mediated feedback messages and operationalized student engagement with feedback messages through their engagement with CTAs, as commonly done in the marketing domain (Gunelius, 2018, p. 25-27). Using this approach, the current paper addresses the following three research questions:

- RQ1. What is the association between student engagement with feedback and their academic success?

- RQ2. What is the association between student engagement with feedback and student characteristics?

- RQ3. How do students perceive personalized feedback emails containing a CTA sent via email?

By exploring student engagement with feedback, we help educators and educational designers understand the nuances of feedback recipience in technology-mediated settings, ultimately narrowing the feedback gap. These questions create a foundation for necessary future research, because a fine-grained analysis of student engagement data at the CTA level remains unexamined by the learning analytics literature.

\section{Methods}

\subsection{Study Context}

The study was carried out in two courses at a large public research university in Australia in the summer term of 2019. To improve the generalizability of the study results, we selected two courses with different course designs and delivery modes. The first course was an introductory bioscience course offered in the blended mode, combining both face-to-face and online learning activities. The course covered the basics of life sciences and living organisms, as well as the fundamentals of the scientific method. The second course was a fully online marketing course covering the fundamentals of marketing, delivered to undergraduate students enrolled in business and information technology schools. In total, there were 218 students in the blended bioscience course and 78 students in the fully online marketing course. Prior to starting the current research, the required ethics clearance was granted by the university internal review board.

It should be noted that participants across both courses consisted of a wide range of students from diverse backgrounds, who often struggled with their learning, making the courses suitable arenas for the provision of scalable feedback and support. The bioscience course was available to students pursuing alternative pathways toward a bachelor's degree and, as such, did not have entry prerequisites. Students could enrol in the course regardless of their educational background, even without completing high school, since such study pathways have been designed to help non-traditional students access undergraduate education. Similarly, the marketing course was part of fully online degree programs designed for non-traditional learners in which they could enrol regardless of their educational background. In both cases, the failure to effectively support these students may make them less likely to pass the course. This is particularly true for the bioscience course, where receiving insufficient support could easily discourage students — especially women, minorities, and other under-represented groups-from pursuing further education (McKay et al., 2012).

ISSN 1929-7750 (online). The Journal of Learning Analytics works under a Creative Commons License, Attribution - NonCommercial-NoDerivs 3.0 Unported 


\subsubsection{Implementation of Feedback Interventions}

To examine feedback recipience in the bioscience course, we focused on two summative quiz activities during the 13 weeks of the course. The two quiz activities focused on assessing basic scientific and mathematical skills and were together worth $25 \%$ of the final course grade ( $12.5 \%$ each). Both quizzes were implemented as 30-45 min open-book Moodle LMS quizzes, allowing students one attempt per quiz. Quiz 1 covered materials from the first five weeks of the course and was due by the end of week 6. Similarly, quiz 2 covered materials from weeks 6 to 11 and was due by the end of week 12 .

Starting from week 3, the instructor implemented a personalized feedback intervention, consisting of feed-forward, processoriented (Hattie \& Timperley, 2007) messages focusing on students' individual learning activities. The goal of feedback intervention was to help students complete different learning activities and regulate their learning by recommending learning activities each week as well as giving feedback on their activity in the previous week. For example, in the first message sent during week 3, students were instructed to explore learning resources relevant to completing the first quiz. Then the following week, the instructor reminded students that they had not accessed those materials (if they had not clicked on the link in the email) or congratulated them on completing the previous week's activity (if they had clicked on the email link). The feedback was provided weekly, aligning with the weekly course structure and student course communication expectations. Messages also included links and reminders for practice quizzes, to help students engage with formative assessment activities. Moreover, the feedback on engagement in the previous week and expectations for the current week enabled students to regulate their learning (Winne \& Hadwin, 1998; Butler \& Winne, 1995), which is known to be associated with better learning outcomes (Bjork et al., 2013). The first CTA message for quiz 1 was not sent until week 3 due to general course email messages and announcements sent in the initial weeks as students oriented themselves with the course and their enrolment. There was also a week break before the first message for quiz 2 due to other competing course assessments at that time, and therefore the initial quiz 2 messages were not sent until week 9. As a result, there was no feedback message in week 8 of the course.

Following a similar approach, in the marketing course, the instructor sent students emails about two course assignments. Assignment 1 (40\% of the final grade) was an 1,800-word written report on a particular marketing issue selected by each student and was due in week 3. Similarly, assignment 2 (60\% of the final grade) was a 2,700-word report describing in detail a marketing plan for a new company and was due in week 5. For each assignment, students received an initial email including a link to the assignment requirements. The subsequent emails provided feedback on students' activity in the previous week and directed them to visit tips for choosing their project topic and writing the final report. The purpose of these emails was to encourage students to engage early in learning, allowing them to learn more and solve any issue before submitting the report.

In both courses, the instructors sent feedback messages to students each week via email using the OnTask (Pardo et al., 2018) platform. OnTask allows educators to monitor student engagement and to program conditional rule sets to send customized feedback emails to students based on their engagement in previous weeks. The OnTask editor also allows for personalized student messages and insertion of HTML links into email messages, so it was well suited to this study. A sample feedback email is shown in Figure 1; note that HTML was styled using inline CSS styles, so they appear as buttons rather as simple HTML links. These feedback messages needed to be actionable, so they were kept clear and succinct; email messages were short and centred around the action that students were supposed to take next. The explicit CTA at the bottom of the email contained a trackable link that directed students to the next suggested activity, making it easy for them to engage in a particular learning activity and monitor their engagement (Pardo et al., 2018). Finally, students who did not complete a task received a reminder email five days later. The CTA was created by adding a new URL resource (Moodle, 2019), which redirects students to a specific LMS page. This was done to distinguish access to learning resources directly from within the LMS and access originating from the feedback messages. The new URL resources were not displayed within the LMS and could only be accessed by students who had a direct link from a feedback message. This made activity tracking for each student simple and clear, readily achieved using a combination of existing OnTask and Moodle LMS functionalities.

\subsection{Data Collection and Analysis}

In this study, we collected measures of student feedback engagement, academic success, and demographics. Student feedback engagement was operationalized in terms of their clicks on CTA links within feedback messages, while academic success was operationalized as passing or failing the course, derived from students' final course grades. The summary of demographics is shown in Table 1. Grade point average (GPA) and English at home were removed from the predictors in the bioscience and marketing course, respectively, because the data points were unevenly distributed across categories. The demographic and grade data was obtained from the student information system, while students' engagement with the feedback messages was collected from the OnTask and Moodle LMS platforms.

To answer RQ1 and RQ2, we used logistic regression, which is a widely used method for predicting binary outcome variables due to its high predictive power and intuitive interpretation (Friedman, Hastie, \& Tibshirani, 2001). To answer RQ1, we used clicks on each of the CTAs as predictors of students' final course grade. To answer RQ2, we used demographic variables listed in Table 1 to predict student engagement with the feedback in the following week. In addition, each subsequent 


\begin{abstract}
Hi David,
Well done to review a few key resources for Bioscience! Quiz 2 is coming up soon and it's time to try the practice quiz. This practice will be very helpful for you to get the best marks that you can. Just like before, feel free to attempt the practice quiz multiple times to properly prepare and be ready for Quiz 2.
\end{abstract}

Now that you are aware of the specifics for Quiz 2, you might want to also revisit key resources on the course page that will ensure proper preparation to really do well and maximise your marks.

Any questions or worries please get in contact.

Take Practice Quiz for Quiz 2!

Kind regards,

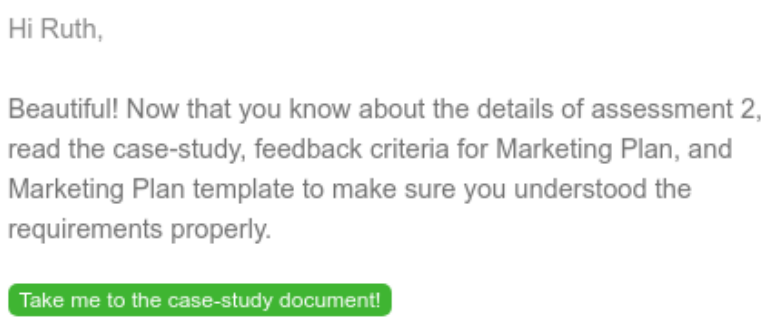

Best wishes,

(a) The bioscience course

(b) The marketing course

Figure 1. Sample feedback messages. In both courses, messages refer to students' activity in the previous week and also recommend the activity for the current week.

week included feedback engagement from previous weeks as binary predictors. For each model, all the predictors were put in the generalized linear model using the $\mathrm{glm}$ function in the R statistical package (R Core Team, 2019). For model evaluation, accuracy was calculated using base R, while the area under the curve (AUC) of the ROC plot was calculated using the pROC package (Robin et al., 2011). Finally, to answer RQ3, we conducted two focus groups with students to gather their perceptions of the feedback messages. Since the use of CTA links is new in the context of providing feedback in education, the purpose of these focus groups was to grasp whether or not students would find the provided feedback helpful. At the end of each course, all students were invited via email to participate in the focus group study and share their experiences with course feedback messages. While we wanted to conduct focus groups with students from both courses, due to the lack of volunteers from the marketing course, we conducted two focus groups with only the students from the bioscience course, with eight and five students, respectively. The focus group discussions lasted approximately one hour, and participants were given $\$ 20$ gift vouchers for their participation. During the focus groups, generic questions were asked about difficulties or concerns that students encountered, about whether feedback helped them reach their learning objectives, and about the contribution of the feedback to their success in the course. Students' responses in the focus groups were analyzed thematically to identify prominent themes. The process was repeated until no more themes were derived, as suggested by Lacey and Luff (2001).

\section{Results}

\subsection{RQ1: The Association between Student Engagement with Feedback and Passing the Course}

To explore associations between weekly engagement with feedback and students successfully passing the course, a logistic regression model with students' weekly feedback engagement as predictors and passing the course as the dependent variable was conducted for the two courses separately (see Table 2). Overall, both models achieved classification accuracy of 0.68 , with F scores of 0.64 and 0.7 and AUC (area under the curve) of 0.71 and 0.66 , respectively. In the bioscience course, from all predictors, the only two that were significant were engagement with the initial emails for both quiz 1 and quiz 2, providing initial recommendations to explore different learning activities. Students who engaged with this first week 3 email were 2.25 times as likely to pass the course, while students who engaged with the first quiz email in week 9 were 4.14 times as likely to pass the course. This pattern was not found in the second course; for the marketing course only engagement with week 3 emails was associated with higher grades; students who engaged with week 3 feedback emails were 4.37 times as likely to score higher as the students that took no action in response to the email.

\subsection{RQ2: The Association between Student Characteristics and Feedback Engagement}

We also examined the association between different student characteristics and feedback engagement. For the bioscience course, we built nine logistic regression models predicting students' weekly engagement with feedback using the set of student demographics described in Table 1. To take into account the longitudinal nature of engagement with feedback over the entire 
Table 1. Descriptive statistics for predictors

(a) The bioscience course

\begin{tabular}{llrr}
\hline Variable & Value & Freq. Percentage $\%$ \\
\hline Admission basis & Secondary education & 44 & 20 \\
& VET & 29 & 13 \\
& Mature-age & 8 & 3 \\
& Other & 137 & 62 \\
\hline Attendance & Full-time & 203 & 93 \\
& Part-time & 15 & 6 \\
English at home & Yes & 182 & 83 \\
& No & 36 & 16 \\
Gender & Male & 75 & 34 \\
& Female & 143 & 65 \\
Previous GPA & GPA available & 37 & 16 \\
& Missing & 181 & 83 \\
Mature age & Yes & 37 & 16 \\
& No & 181 & 83 \\
\hline Previous attainment & Secondary education & 112 & 51 \\
& Some college & 12 & 5 \\
& VET course & 68 & 31 \\
& Nothing & 26 & 11 \\
\hline \multirow{2}{*}{ Study program } & Diploma & 80 & 36 \\
& Foundation & 138 & 63 \\
\hline
\end{tabular}

(b) The marketing course

\begin{tabular}{llrr}
\hline Variable & Value & Freq. Percentage $\%$ \\
\hline Admission basis & Secondary education & 17 & 21 \\
& VET & 19 & 24 \\
& Some college & 19 & 24 \\
& Other & 23 & 29 \\
\hline Attendance & Full-time & 40 & 51 \\
& Part-time & 38 & 48 \\
English at home & Yes & 77 & 98 \\
& No & 1 & 1 \\
Gender & Male & 25 & 32 \\
& Female & 53 & 67 \\
Previous GPA & GPA available & 54 & 70 \\
& Missing & 24 & 30 \\
\hline Mature age & Yes & 46 & 58 \\
& No & 32 & 41 \\
\hline Previous attainment & Secondary education & 13 & 16 \\
& Some college & 34 & 43 \\
& VET course & 21 & 26 \\
& Nothing & 10 & 12 \\
\hline Study program & Management & 11 & 14 \\
& Human Resources & 11 & 14 \\
& Marketing & 19 & 24 \\
& Accounting & 30 & 38 \\
& IT \& Communication & 7 & 8 \\
\hline
\end{tabular}

Notes: VET: Vocational Education and Training.

course, we also included as predictors students' engagement with feedback in previous weeks. Similarly, for the marketing course, five logistic regression models were used to predict engagement with the email CTAs. The model fit indices are shown in Table 3, while the significant predictors are shown in Table 4 and Table 5. The detailed data for significant differences are included in the Appendix, in Tables 6 and 7.

As shown in Table 3, for the bioscience course, all models achieved high accuracy, ranging from $63 \%$ for week 3 to $100 \%$ for week 12. However, F1 scores, which are robust measures of the quality of model prediction, range from 0.55 for week 3 to 0.09 for week 7 . Except for the anomaly for week 12, F1 scores are decreasing for engagement with individual quizzes, which are highest for weeks 3 and 9. In the marketing course, the model accuracy is between 0.67 and 0.86 , with F1 scores between 0.39 and 0.56 and AUC between 0.72 and 0.93 . One interesting pattern that showed up in both courses is the general increase in model accuracy and AUC. This pattern might be attributed to the fact that as we move forward in the semester, we have more behavioural student engagement data with email CTAs, which adds to the predictive power of models for upcoming weeks.

Looking at results from both courses (Table 4 and Table 5), the strongest—albeit inconsistent—predictor of feedback engagement was prior engagement with the feedback, especially early in the course. In the bioscience course, feedback

Table 2. Logistic regression results for predicting passing the course with weekly feedback engagement

(a) The bioscience course

\begin{tabular}{lrrrr}
\hline Predictor & OR & SE & \multicolumn{1}{c}{ Stat. } & $p$ \\
\hline Week 3 feedback engagement (Quiz 1) & $\mathbf{2 . 2 5}$ & $\mathbf{0 . 3 7}$ & $\mathbf{2 . 2 2}$ & $\mathbf{0 . 0 3 *}$ \\
Week 4 feedback engagement (Quiz 1) & 0.82 & 0.48 & -0.41 & 0.68 \\
Week 5 feedback engagement (Quiz 1) & 0.92 & 0.45 & -0.20 & 0.84 \\
Week 6 feedback engagement (Quiz 1) & 1.68 & 0.58 & 0.90 & 0.37 \\
Week 7 feedback engagement (Quiz 1) & 1.42 & 0.40 & 0.88 & 0.38 \\
\hline Week 9 feedback engagement (Quiz 2) & $\mathbf{4 . 1 4}$ & $\mathbf{0 . 5 7}$ & $\mathbf{2 . 5 0}$ & $\mathbf{0 . 0 1 *}$ \\
Week 10 feedback engagement (Quiz 2) & 1.97 & 0.58 & 1.18 & 0.24 \\
Week 11 feedback engagement (Quiz 2) & 0.52 & 0.72 & -0.91 & 0.36 \\
Week 12 feedback engagement (Quiz 2) & 0.67 & 0.78 & -0.51 & 0.61 \\
\hline
\end{tabular}

(b) The marketing course

\begin{tabular}{lrrrr}
\hline Predictor & OR & SE & Stat. & $p$ \\
\hline Week 1 feedback engagement (Assessment 1) & 0.96 & 0.58 & -0.07 & 0.94 \\
Week 2 feedback engagement (Assessment 1) & 1.39 & 0.54 & 0.60 & 0.55 \\
Week 3 feedback engagement (Assessment 1) & $\mathbf{4 . 3 7}$ & $\mathbf{0 . 6 4}$ & $\mathbf{2 . 3 1}$ & $\mathbf{0 . 0 2}$ \\
\hline Week 4 feedback engagement (Assessment 2) & 0.88 & 0.62 & -0.21 & 0.84 \\
Week 5 feedback engagement (Assessment 2) & 1.47 & 0.66 & 0.58 & 0.56 \\
\hline & & & &
\end{tabular}


Table 3. Results of weekly logistic regression models.

(a) The bioscience course

\begin{tabular}{lrrr}
\hline Outcome Variable & Accuracy & F1 & AUC \\
\hline Week 3 feedback engagement (Quiz 1) & 0.63 & 0.55 & 0.68 \\
Week 4 feedback engagement (Quiz 1) & 0.69 & 0.43 & 0.83 \\
Week 5 feedback engagement (Quiz 1) & 0.68 & 0.27 & 0.74 \\
Week 6 feedback engagement (Quiz 1) & 0.71 & 0.22 & 0.78 \\
Week 7 feedback engagement (Quiz 1) & 0.73 & 0.09 & 0.79 \\
Week 9 feedback engagement (Quiz 2) & 0.75 & 0.31 & 0.81 \\
Week 10 feedback engagement (Quiz 2) & 0.77 & 0.29 & 0.84 \\
Week 11 feedback engagement (Quiz 2) & 0.81 & 0.13 & 0.88 \\
Week 12 feedback engagement (Quiz 2) & 1.00 & 0.20 & 1.00 \\
\hline
\end{tabular}

(b) The marketing course

\begin{tabular}{lrrr}
\hline Outcome Variable & Accuracy & F1 & AUC \\
\hline Week 1 feedback engagement (Assessment 1) & 0.67 & 0.42 & 0.72 \\
Week 2 feedback engagement (Assessment 1) & 0.79 & 0.56 & 0.85 \\
Week 3 feedback engagement (Assessment 1) & 0.86 & 0.42 & 0.92 \\
Week 4 feedback engagement (Assessment 2) & 0.86 & 0.45 & 0.89 \\
Week 5 feedback engagement (Assessment 2) & 0.83 & 0.39 & 0.93 \\
\hline
\end{tabular}

engagement in week 3 (first week of intervention) was a statistically significant predictor of student feedback engagement in weeks 4 to 6 . In contrast, engagement with week 4 feedback was the only significant predictor of week 9 feedback engagement, with students who engaged with week 4 feedback being more than five times as likely to engage with week 9 feedback. Similarly, students who engaged with week 5 feedback were 3.26 times as likely to engage with week 10 messages. Students who engaged with week 6 were over six times as likely to engage with week 10 and week 11 feedback. Finally, students that engaged with week 9 feedback were over 6 and 14 times as likely to engage with feedback in weeks 10 and 11, respectively. Similar patterns were observed in the marketing course, with week 1 engagement being the most significant predictor of future feedback engagement. Students who engaged with week 1 feedback were 4.85 and 13 times as likely to engage with week 2 and week 3 feedback, respectively. Similarly, week 2 feedback engagement was the significant predictor of the engagement in week 4, with students who engaged with week 2 feedback being over 10 times as likely to engage with week 4 feedback.

Besides the feedback engagement in previous weeks, we see a significant association between student demographics and their feedback engagement (Table 4 and Table 5). In the bioscience course, female students were more than twice as likely to engage with feedback in week 3 and week 9 , while culturally and linguistically diverse (CALD) students were 4.5 times as likely to engage with week 7 feedback. Finally, mature students and students who did not have any previous attainment were about one quarter as likely to engage with week 10 feedback messages. In the marketing course, students who had previously attained a feedback-engaged (VET) qualification were 9.83 times as likely to engage with provided feedback. We also see that part-time students are 11.36 times as likely to engage with week 3 emails as full-time students. Students who have some college background or no previous attainment were much less likely to engage with week 3 emails, and students who entered university through other admission pathways were over 15 times as likely to engage with week 3 messages.

\subsection{RQ3: Students' Perception of CTAs in Personalized Feedback Messages}

To examine student perceptions of actionable CTAs in feedback messages, we conducted two focus groups with participants from the bioscience course, with eight and five students, respectively. Students expressed a wide variety of opinions about the course and the feedback. The following themes emerged in the bioscience course focus groups: the challenges presented by the course, feedback email messages as reminders, and links in engaging with the course.

- Challenges presented by the course: Students found the course challenging and hard, especially those who had not completed chemistry or biology subjects in high school. They mentioned that attending the lectures and tutorials helped them understand the contents of the course. Interacting with fellow students also helped struggling students to learn in this course.

- Feedback email messages as reminders: Personalized feedback emails helped students evaluate their progress in the course and get back on track in case they were falling behind. One student said, "It made sure I got things done because I'm a big procrastinator." Another student described her feelings when opening the emails: "So when I got them, I was like, oh this is overwhelming, and then I was like, no. And then I just kinda deleted them [respondents laugh]. But like a few of 'em were good. A few of them would pop up and be like, you got an email from the co-ordinator, which was helpful. And every time that came up I was like, oh this must be important." However, the feeling changed after acting on the feedback: "once you like clicked on it you're like, okay I've done it, it's done."

- The role of links in engaging with the course: Students mentioned that the links made the emails easy to understand and act upon. One student said, "I guess if you're lazy, you just click it and you know where it is [laughs] so easier." Another student mentioned "They kinda help because they take you straight there instead of having to go through." Another student described the role of links in her own words: "You're just reading then oh you know exactly what she meant." 
Table 4. The bioscience course-Odds ratios for nine logistic regression models predicting weekly feedback engagement using demographic and feedback engagement predictors. Boldface* represents significance at the $p<0.05$ level.

\begin{tabular}{|c|c|c|c|c|c|c|c|c|c|}
\hline \multirow[b]{2}{*}{ Predictor variable } & \multicolumn{9}{|c|}{ Week $N$ Feedback Engaged (Binary outcome variable) } \\
\hline & Week 3 & Week 4 & Week 5 & Week 6 & Week 7 & Week 9 & Week 10 & Week 11 & Week 12 \\
\hline Attendance $=$ Part-time & 0.89 & 0.74 & 0.77 & 0.88 & NA & 0.66 & 2.12 & 0.44 & 1.00 \\
\hline Gender $=$ Female & $2.35 *$ & 0.55 & 1.23 & 2.59 & 2.43 & $2.78 *$ & 1.07 & 0.55 & 1.00 \\
\hline English at home $=$ No & 0.70 & 1.36 & 2.34 & 1.65 & 4.58* & 1.26 & 1.14 & 1.18 & 1.00 \\
\hline Mature $=$ No & 0.67 & 0.46 & 1.32 & 0.44 & 1.09 & 0.89 & $0.26 *$ & 0.73 & 1.00 \\
\hline Program $=$ Foundation & 0.78 & 18.61 & 2.83 & 0.43 & 0.51 & 1.16 & 0.64 & 0.55 & 1.00 \\
\hline Admission basis $=$ VET & 0.65 & 1.31 & 1.54 & 3.15 & 1.74 & 1.04 & 0.68 & NA & 1.00 \\
\hline Admission basis $=$ Mature age & 2.05 & 0.27 & 1.48 & 0.95 & 9.97 & 0.30 & 0.59 & 9.22 & 1.00 \\
\hline Admission basis $=$ Other & 0.49 & 0.04 & 0.23 & 1.51 & 1.64 & 0.93 & 3.97 & 1.03 & 1.00 \\
\hline Previous attainment $=$ Some college & 0.69 & 0.07 & 1.37 & NA & NA & 1.91 & NA & NA & 1.00 \\
\hline Previous attainment $=$ VET course & 1.56 & 0.61 & 0.64 & 0.27 & 0.56 & 1.01 & 0.79 & 3.05 & 1.00 \\
\hline Previous attainment $=$ Nothing & 0.62 & 1.21 & 0.78 & 0.74 & 0.76 & 3.48 & $0.17 *$ & 0.29 & 1.00 \\
\hline \multicolumn{10}{|c|}{ Engagement with feedback in previous weeks (binary predictor) } \\
\hline Week 3 feedback engaged & & $27.75 *$ & $2.86 *$ & $5.33 *$ & 2.81 & 2.00 & 2.12 & 0.47 & 1.00 \\
\hline Week 4 feedback engaged & & & 2.16 & 0.34 & 0.57 & $5.62 *$ & 0.56 & 0.73 & 1.00 \\
\hline Week 5 feedback engaged & & & & 1.50 & 0.62 & 1.86 & $3.26 *$ & 0.79 & 1.00 \\
\hline Week 6 feedback engaged & & & & & 2.06 & 0.97 & $6.31 *$ & $6.59 *$ & 1.00 \\
\hline Week 7 feedback engaged & & & & & & 1.24 & 2.84 & NA & 1.00 \\
\hline Week 9 feedback engaged & & & & & & & $6.38 *$ & $14.34 *$ & 1.00 \\
\hline Week 10 feedback engaged & & & & & & & & 1.02 & 1.00 \\
\hline Week 11 feedback engaged & & & & & & & & & 1.00 \\
\hline
\end{tabular}

Notes: Baseline for Admission basis = Secondary education; Baseline for Previous attainment = Secondary education; VET: Vocational Education and Training.

\section{Discussion}

Our first research question focused on the relationship between student engagement with feedback CTAs and passing the course. According to RQ1 results (Table 2), for the bioscience course, acting upon the first email in each set of messages (via clicking the first CTA) was positively associated with passing the course, making early engagement with feedback messages a predictor of student outcomes. Our results indicate that students who engage with the feedback early in the course have higher chances of passing the course, which might be because the feedback messages nudged students to engage early with the course and study regularly throughout the semester (Lim et al., 2019). Early engagement may also create more time for spaced learning, interleaving, and other learning strategies that are associated with higher retention in the long run (Bjork et al., 2013). For the marketing course, this pattern was observed with a two-week delay, so students who engaged with week 3 emails (as opposed to week 1) were more than four times as likely to pass the course. While this warrants further research and examination, one explanation for this delay might be the differences in student populations. The marketing course is online (versus a blended course such as the bioscience course), and the student cohort comprised more mature students (58\% in the marketing course versus $16 \%$ in the bioscience course) and more part-time students (48\% in the marketing course versus $6 \%$ in the bioscience course) (see Table 1), so we might speculate that students in the marketing course are more likely to be older and have full-time jobs and other commitments, and their limited time does not allow them to engage early with the messages, so they engage "just in time" to complete and submit their graded assignments. Another explanation might be the prior knowledge of students, since online students are more likely to have professional experience, so they may not have felt the need to engage early in the course. This pattern was observed in previous studies, such as Kovanović, Gašević, Joksimović, Hatala, and Adesope (2015), where students with a good prior knowledge had minimal engagement with the course but completed the course successfully. Similarly, the different design of the two courses (one blended and one fully online), as well as the different design of the specific learning activities, could also contribute to the observed differences in student engagement with the feedback (Nguyen, Rienties, Toetenel, Ferguson, \& Whitelock, 2017; Nguyen, Huptych, \& Rienties, 2018). Given the critical importance of learning design for the success of learning analytics interventions (Lockyer \& Dawson, 2011), further research is needed to examine how learning design considerations affect student engagement with feedback.

The second research question explored the feedback engagement patterns of different student demographic groups, because we believe it would be useful for educators to identify students who may have specific challenges with feedback engagement. 
Table 5. The marketing course-Odds ratios for five logistic regression models predicting weekly feedback engagement using demographic and feedback engagement predictors. Boldface represents significance at $p<0.05$ level.

\begin{tabular}{|c|c|c|c|c|c|}
\hline \multirow[b]{2}{*}{ Predictor variable } & \multicolumn{5}{|c|}{ Week $N$ Feedback Engaged (Binary outcome variable) } \\
\hline & Week 1 & Week 2 & Week 3 & Week 4 & Week 5 \\
\hline Attendance $=$ Part-time & 1.17 & 1.24 & 11.36* & 0.62 & 1.96 \\
\hline Gender $=$ Female & 1.40 & 1.92 & 1.71 & 4.33 & 14.01 \\
\hline Mature $=$ No & 0.50 & 0.67 & 1.57 & 0.66 & 0.10 \\
\hline Admission basis $=$ VET & 0.18 & 0.39 & 3.96 & 8.61 & 0.02 \\
\hline Admission basis $=$ Some college & 0.72 & 0.73 & 8.81 & 7.93 & 2.10 \\
\hline Admission basis $=$ Other & 1.56 & 0.18 & 15.38* & 2.99 & 0.15 \\
\hline Previous GPA $=$ Missing & 0.46 & 1.51 & $0.07 *$ & 0.73 & 0.03 \\
\hline Previous GPA = Below_median & 0.50 & 1.48 & 1.27 & 0.75 & 4.39 \\
\hline Previous attainment $=$ Some college & 4.07 & 0.16 & $0.04 *$ & 0.43 & 49.43 \\
\hline Previous attainment $=$ VET course & $9.83 *$ & 1.55 & 0.22 & 0.19 & 34.43 \\
\hline Previous attainment $=$ Nothing & 2.57 & 0.47 & $0.01 *$ & 2.05 & 219.27 \\
\hline Program $=$ Accounting & 1.73 & 0.94 & 1.55 & 0.54 & 1.93 \\
\hline Program $=$ Human Resources & 0.64 & 0.52 & 1.39 & 0.00 & 0.29 \\
\hline Program $=$ IT \& Communication & 2.14 & 0.49 & 16.93 & 2.73 & 0.00 \\
\hline Program $=$ Marketing & 1.20 & $\mathbf{0 . 0 7 *}$ & 6.62 & 0.32 & 0.45 \\
\hline \multicolumn{6}{|c|}{ Engagement with feedback in previous weeks (binary predictor) } \\
\hline Week 1 feedback engagement & & $4.85 *$ & 13.06* & 0.77 & 1.18 \\
\hline Week 2 feedback engagement & & & 4.02 & $10.37 *$ & 1.87 \\
\hline Week 3 feedback engagement & & & & 3.21 & 6.98 \\
\hline Week 4 feedback engagement & & & & & 3.93 \\
\hline
\end{tabular}

Notes: Baseline for Admission basis = Secondary education; Baseline for Previous attainment = Secondary education;

VET: Vocational Education and Training.

In our study, with the bioscience group, the association of feedback engagement with student demographics was sporadic, with no consistent association over time (Table 4). The only pattern belonged to female students, who were more likely to engage in week 3 and week 9, corresponding to the first successive messages for quiz 1 and 2, respectively, and CALD students showed higher engagement in week 7 , and the engagement of mature students was lower in week 10. These findings for female students are aligned with previous research by Turner and Gibbs (2010), who suggest that female students are more likely to act on feedback. However, this pattern of higher female engagement was not observed in the second group, the marketing course. Therefore, based on these two studies, previous engagement remains the most important variable for predicting student engagement with future customized feedback messages.

Finally, the third research question focused on student perceptions of feedback messages, including CTA links. As discussed in the results section, three themes were drawn out of the focus group data. Two of these themes already feature in education literature: introductory science courses are known to be challenging for students (McKay et al., 2012), and previous research into customized feedback messages has revealed that feedback messages help students track their progress (Pardo et al., 2019). However, the third theme-exploring the value of links to students - is new to education and provides novel insights into students' engagement with feedback messages containing CTAs. The value of making messages easy and saving users' time is well recognized in digital marketing (Szymanski \& Hise, 2000; Sharp, 2017), and it was beneficial to have this confirmed by students as users of the feedback system.

\section{Limitations}

The present study has some limitations. First, the patterns observed in this study originate from two small student cohorts with a specific kind of feedback and thus are not generalizable to other learning contexts. Each course is a unique learning experience, and student engagement with feedback is a function of many factors (e.g., teaching method, course structure, timing of emails, appropriate subject lines) that cannot be examined in a single study. Future research in this area will uncover which patterns will show up in different situations. Second, while logistic regression is a simple and widely used modelling technique, it is also possible that the relatively small size of student cohorts has impacted some of the findings of our study, especially given the lower number of clicks in the latter weeks of the courses. As a result, the findings presented in this study should be 
treated as exploratory, and future work should focus on confirming some of the patterns identified in the present study.

Similarly, the associations found in this study have a correlational nature, and causal relationships could not be inferred from an observational study like the current research paper. For example, we cannot infer that engaging with these feedback messages caused students to pass the course, nor can we conclude that students engaged with these feedback messages because they have already engaged with the learning activities suggested in the previous messages. Therefore, we must be careful when interpreting the results of observational studies; we can only imply a correlation, not causation. Correlation is a necessary but not sufficient condition of causation (Rodgers \& Nicewander, 1988). In other words, this study does not answer the question, "Are the personal feedback messages containing CTAs getting students to engage with learning activities who would not have done those activities anyway?" This point is a caveat in evaluating the impact of digital marketing activities as well: "Are the ads getting people to buy stuff who would not have bought that stuff anyway?" (O'Neil, 2013, p. 9). Future studies can answer this question through careful experimental design and investigate whether engaging with feedback messages leads to greater academic outcomes, or whether the students that engage are those that were the high achievers in a cohort. Future studies could also further compare the differences in the effectiveness of actionable feedback between online and traditional modes of study. Comparing the same course in two different environments would also provide better insight into the results, which is currently an additional limitation of this study.

Finally, we recognize the limitations of the proxy used for student feedback in this study, and we acknowledge that clicking a CTA link does not necessarily mean that action was taken nor that learning happened. Human learning is inherently complex, and no measure can capture this complexity perfectly. However, these measures of student engagement with feedback represent useful proxies that enable us to improve our understanding of human learning and interaction with the feedback, and the present study sets out a robust methodology for future research. One scenario for improving the proxy in the future is to augment our dataset with other datasets or other measures of engagement, such as the time interval between the first engagement and completing that learning activity (such as first clicking on the quiz link and submitting the quiz) or student engagement in general after the first click on the CTA for that week. These proxies may help us delve deeper into the impacts of actionable feedback messages and fine-tune our feedback system to maximize our support for students. Similarly, a more in-depth study looking at the value of provided CTA links would enable us to examine the usefulness of provided feedback messages after students engage with them.

\section{Conclusion}

The present study makes two main contributions: (1) empirically examining student engagement with technology-mediated feedback and (2) laying the methodological groundwork for future empirical analyses of student engagement with technologymediated feedback. To the best of our knowledge, this is the first study to use an empirical methodology to examine student engagement with technology-mediated feedback. While previous studies have examined student perceptions of feedback, we tracked student engagement with feedback messages, looking at the relationship with both student demographic characteristics and student success defined as passing the course. This study outlines a methodology for using the OnTask and Moodle platforms to run similar analyses in the future; this approach uses simple and handy functionalities that are already familiar to most online educators. While this study is a first step toward understanding students' engagement with feedback messages, we hope that in the future, similar studies will offer new insight into the complexities of feedback provision in technology-mediated settings.

The findings of our study confirm existing literature around self-regulated learning skills and the role of proper time management in student learning (Winne \& Hadwin, 1998; Butler \& Winne, 1995) and show that early feedback engagement is associated with passing the course. Further improving educators' understanding of feedback provision in technology-mediated settings using this methodology would create the potential for early intervention and support for students who are likely to fall behind in their studies - students who do not engage with early feedback. We further demonstrated that making feedback messages actionable has experiential and analytical benefits. Actionable feedback messages improve student learning experiences by directing them to the next suggested learning activity in an easy and seamless way, helping them with their time management. The actionability of feedback messages also offers analytical benefits, since educators and researchers can track student engagement with feedback, finding previously undiscovered patterns in the data that can become a stepping stone to continuously improving the feedback system and narrowing the feedback gap. Applying a data-driven approach to improving feedback processes and narrowing the feedback gap by using trackable CTAs in customized email messages was well received by students. These methods allowed the researchers to quantitatively explore student reactions to feedback messages, establish a methodology for discovering patterns, design interventions, and improve feedback recipience for students of different backgrounds. The current paper demonstrates that the popular and tried-and-true digital marketing method of collecting data on actions on feedback messages is applicable to education, which has great potential to help researchers understand feedback recipience at a deeper level and narrow the feedback gap.

ISSN 1929-7750 (online). The Journal of Learning Analytics works under a Creative Commons License, Attribution - NonCommercial-NoDerivs 3.0 Unported (CC BY-NC-ND 3.0) 


\section{Declaration of Conflicting Interest}

The authors declared no potential conflicts of interest with respect to the research, authorship, and/or publication of this article.

\section{Funding}

The authors declared no financial support for the research, authorship, and/or publication of this article.

\section{References}

Applegate, E. (2005). Strategic copywriting: How to create effective advertising. Lanham, MD, USA: Rowman \& Littlefield. Arnold, K. E., \& Pistilli, M. D. (2012). Course signals at Purdue: Using learning analytics to increase student success. In Proceedings of the Second International Conference on Learning Analytics and Knowledge (LAK '12), 29 April-2 May 2012, Vancouver, Canada (pp. 267-270). New York: ACM. https://doi.org/10.1145/2330601.2330666

Bjork, R. A., Dunlosky, J., \& Kornell, N. (2013). Self-regulated learning: Beliefs, techniques, and illusions. Annual Review of Psychology, 64(1), 417-444. https://doi.org/10.1146/annurev-psych-113011-143823

Boud, D., \& Molloy, E. (2013a). Feedback in higher and professional education: Understanding it and doing it well. New York, USA: Routledge.

Boud, D., \& Molloy, E. (2013b). Rethinking models of feedback for learning: The challenge of design. Assessment \& Evaluation in Higher Education, 38(6), 698-712. https://doi.org/10.1080/02602938.2012.691462

Broos, T., Peeters, L., Verbert, K., Van Soom, C., Langie, G., \& De Laet, T. (2017). Dashboard for actionable feedback on learning skills: Scalability and usefulness. In P. Zaphiris \& A. Ioannou (Eds.), Learning and collaboration technologies. Technology in education (pp. 229-241). Vancouver, BC, Canada: Springer International Publishing. https://doi.org/10.1007/978-3-319-58515-4_18

Butler, D. L., \& Winne, P. H. (1995). Feedback and self-regulated learning: A theoretical synthesis. Review of Educational Research, 65(3), 245-281. https://doi.org/10.3102/00346543065003245

Carless, D. (2020). Longitudinal perspectives on students' experiences of feedback: A need for teacher-student partnerships. Higher Education Research \& Development, 39(3), 1-14. https://doi.org/10.1080/07294360.2019.1684455

Carless, D., \& Boud, D. (2018). The development of student feedback literacy: Enabling uptake of feedback. Assessment \& Evaluation in Higher Education, 43(8), 1315-1325. https://doi.org/10.1080/02602938.2018.1463354

Chong, S. W. (2019). College students' perception of e-feedback: A grounded theory perspective. Assessment \& Evaluation in Higher Education, 44(7), 1090-1105. https://doi.org/10.1080/02602938.2019.1572067

Chong, S. W. (2020). Reconsidering student feedback literacy from an ecological perspective. Assessment \& Evaluation in Higher Education, 46(1), 1-13. https://doi.org/10.1080/02602938.2020.1730765

Corrin, L., \& de Barba, P. (2014). Exploring students' interpretation of feedback delivered through learning analytics dashboards. In Proceedings of the ASCILITE 2014 Conference, 23-26 November 2014, Dunedin, NZ (pp. 629-633). ASCILITE. Retrieved from https://ascilite.org/conferences/dunedin2014/files/concisepapers/223-Corrin.pdf

Corrin, L., \& de Barba, P. (2015). How do students interpret feedback delivered via dashboards? In Proceedings of the Fifth International Conference on Learning Analytics and Knowledge (LAK 2015), 16-20 March 2015, Poughkeepsie, NY, USA (pp. 430-431). New York: ACM. https://doi.org/10.1145/2723576.2723662

Cugelman, B., Thelwall, M., \& Dawes, P. (2011). Online interventions for social marketing health behavior change campaigns: A meta-analysis of psychological architectures and adherence factors. Journal of Medical Internet Research, 13(1), e17. https://doi.org/10.2196/jmir.1367

Dawson, P., Henderson, M., Ryan, T., Mahoney, P., Boud, D., Phillips, M., \& Molloy, E. (2018). Technology and feedback design. In M. J. Spector, B. B. Lockee, \& M. D. Childress (Eds.), Learning, Design, and Technology (pp. 1-45). Cham, Switzerland: Springer International Publishing. https://doi.org/10.1007/978-3-319-17727-4_124-1

Deighton, J., \& Kornfeld, L. (2009). Interactivity's unanticipated consequences for marketers and marketing. Journal of Interactive Marketing, 23(1), 4-10. (Anniversary Issue) https://doi.org/10.1016/j.intmar.2008.10.001

Ellis, C. (2013). Broadening the scope and increasing the usefulness of learning analytics: The case for assessment analytics. British Journal of Educational Technology, 44(4), 662-664. https://doi.org/10.1111/bjet.12028

Evans, C. (2013). Making sense of assessment feedback in higher education. Review of Educational Research, 83(1), 70-120. https://doi.org/10.3102/0034654312474350

Friedman, J., Hastie, T., \& Tibshirani, R. (2001). The elements of statistical learning (Vol. 1). New York: Springer. https://doi.org/10.1007/978-0-387-84858-7 
Gannaway, D., Green, T., \& Mertova, P. (2018). So how big is big? Investigating the impact of class size on ratings in student evaluation. Assessment \& Evaluation in Higher Education, 43(2), 175-184. https://doi.org/10.1080/02602938.2017.1317327

Gašević, D., Dawson, S., \& Siemens, G. (2015). Let's not forget: Learning analytics are about learning. TechTrends, 59(1), 64-71. https://doi.org/10.1007/s11528-014-0822-x

Gibbs, G., \& Simpson, C. (2005). Conditions under which assessment supports students' learning. Learning and Teaching in Higher Education, 1(1), 3-31. Retrieved from https://eprints.glos.ac.uk/3609/

Glass, R., \& Callahan, S. (2014). The big data-driven business: How to use big data to win customers, beat competitors, and boost profits. Hoboken, NJ, USA: John Wiley \& Sons.

Grann, J., \& Bushway, D. (2014). Competency map: Visualizing student learning to promote student success. In Proceedings of the Fourth International Conference on Learning Analytics and Knowledge (LAK 2014), 24-28 March 2014, Indianapolis, IN, USA (pp. 168-172). New York: ACM. https://doi.org/10.1145/2567574.2567622

Gunelius, S. (2018). Ultimate guide to email marketing for business. Irvine, CA, USA: Entrepreneur Press.

Hanna, R. C., Swain, S. D., \& Smith, J. (2015). Email marketing in a digital world: The basics and beyond. New York: Business Expert Press.

Hartemo, M. (2016). Email marketing in the era of the empowered consumer. Journal of Research in Interactive Marketing, 10(3), 212-230. https://doi.org/10.1108/JRIM-06-2015-0040

Hattie, J. (1999). Influences on student learning. Inaugural Lecture at the University of Auckland, 2 August 1999, Auckland, NZ, 1-25. Retrieved from https://cdn.auckland.ac.nz/assets/education/about/research/documents/influences-on-student-learning.pdf

Hattie, J., \& Timperley, H. (2007). The power of feedback. Review of Educational Research, 77(1), 81-112. https://doi.org/10.3102/003465430298487

Herodotou, C., Heiser, S., \& Rienties, B. (2017). Implementing randomised control trials in open and distance learning: A feasibility study. Open Learning: The Journal of Open, Distance and e-Learning, 32(2), 147-162. https://doi.org/10.1080/02680513.2017.1316188

Howell, J. A., Roberts, L. D., \& Mancini, V. O. (2018). Learning analytics messages: Impact of grade, sender, comparative information and message style on student affect and academic resilience. Computers in Human Behavior, 89, 8-15. https://doi.org/10.1016/j.chb.2018.07.021

Iraj, H., Fudge, A., Faulkner, M., Pardo, A., \& Kovanović, V. (2020). Understanding students' engagement with personalised feedback messages. In Proceedings of the 10th International Conference on Learning Analytics \& Knowledge (LAK 2020), 23-27 March 2020, Frankfurt, Germany (pp. 438-447). New York: ACM. https://doi.org/10.1145/3375462.3375527

Kizilcec, R., \& Brooks, C. (2017). Diverse big data and randomized field experiments in massive open online courses. In C. Lang, G. Siemens, A. F. Wise, \& D. Gaševic (Eds.), The Handbook of Learning Analytics (pp. 211-222). Society for Learning Analytics Research. https://doi.org/10.18608/hla17.018

Kluger, A. N., \& DeNisi, A. (1996). The effects of feedback interventions on performance: A historical review, a meta-analysis, and a preliminary feedback intervention theory. Psychological Bulletin, 119(2), 254-284. https://doi.org/10.1037/0033-2909.119.2.254

Kovanović, V., Gašević, D., Joksimović, S., Hatala, M., \& Adesope, O. (2015). Analytics of communities of inquiry: Effects of learning technology use on cognitive presence in asynchronous online discussions. The Internet and Higher Education, 27, 74-89. https://doi.org/10.1016/j.iheduc.2015.06.002

Krueger, A. B. (1999). Experimental estimates of education production functions. The Quarterly Journal of Economics, 114(2), 497-532. https://doi.org/10.1162/003355399556052

Lacey, A., \& Luff, D. (2001). Qualitative data analysis. Nottingham: Trent Focus Sheffield.

Lim, L.-A., Gentili, S., Pardo, A., Kovanović, V., Whitelock-Wainwright, A., Gašević, D., \& Dawson, S. (2019). What changes, and for whom? A study of the impact of learning analytics-based process feedback in a large course. Learning and Instruction, 72, 101202. https://doi.org/10.1016/j.learninstruc.2019.04.003

Liu, D. Y.-T., Bartimote-Aufflick, K., Pardo, A., \& Bridgeman, A. J. (2017). Data-driven personalization of student learning support in higher education. In A. Peña-Ayala (Ed.), Learning analytics: Fundaments, applications, and trends: A view of the current state of the art to enhance e-learning (pp. 143-169). Cham, Switzerland: Springer International Publishing. https://doi.org/10.1007/978-3-319-52977-6_5

Lockyer, L., \& Dawson, S. (2011). Learning designs and learning analytics. In Proceedings of the First International Conference on Learning Analytics \& Knowledge (LAK 2011), 27 February-1 March 2011, Banff, AB, Canada (pp. 153-156). https://doi.org/10.1145/2090116.2090140 
Long, P., \& Siemens, G. (2011). Penetrating the fog: Analytics in learning and education. EDUCAUSE Review, 46(5), 30-40. https://doi.org/10.17471/2499-4324/195

McKay, T., Miller, K., \& Tritz, J. (2012). What to do with actionable intelligence: $\mathrm{E}^{2}$ coach as an intervention engine. In Proceedings of the Second International Conference on Learning Analytics \& Knowledge (LAK 2012), 29 April-2 May 2012, Vancouver, BC, Canada (pp. 88-91). New York: ACM. https://doi.org/10.1145/2330601.2330627

Molloy, E., Boud, D., \& Henderson, M. (2020). Developing a learning-centred framework for feedback literacy. Assessment \& Evaluation in Higher Education, 45(4), 527-540. https://doi.org/10.1080/02602938.2019.1667955

Moodle. (2019). URL Resource—MoodleDocs. Retrieved from https://docs.moodle.org/37/en/URL_resource

Nguyen, Q., Huptych, M., \& Rienties, B. (2018). Linking students' timing of engagement to learning design and academic performance. In Proceedings of the Eighth International Conference on Learning Analytics \& Knowledge (LAK 2018), 5-8 March 2018, Sydney, Australia (pp. 141-150). https://doi.org/10.1145/3170358.3170398

Nguyen, Q., Rienties, B., Toetenel, L., Ferguson, R., \& Whitelock, D. (2017). Examining the designs of computer-based assessment and its impact on student engagement, satisfaction, and pass rates. Computers in Human Behavior, 76, 703-714. https://doi.org/10.1016/j.chb.2017.03.028

Nicol, D. (2010). From monologue to dialogue: Improving written feedback processes in mass higher education. Assessment \& Evaluation in Higher Education, 35(5), 501-517. https://doi.org/10.1080/02602931003786559

Nicol, D., \& Macfarlane-Dick, D. (2006). Formative assessment and self-regulated learning: A model and seven principles of good feedback practice. Studies in Higher Education, 31(2), 199-218. https://doi.org/10.1080/03075070600572090

O’Neil, C. (2013). On being a data skeptic. Sebastopol, CA, USA: O'Reilly Media.

Pardo, A., Bartimote, K., Shum, S. B., Dawson, S., Gao, J., Gašević, D., .. Vigentini, L. (2018). OnTask: Delivering data-informed, personalized learning support actions. Journal of Learning Analytics, 5(3), 235-249. https://doi.org/10.18608/jla.2018.53.15

Pardo, A., Jovanovic, J., Dawson, S., Gašević, D., \& Mirriahi, N. (2019). Using learning analytics to scale the provision of personalised feedback. British Journal of Educational Technology, 50(1), 128-138. https://doi.org/10.1111/bjet.12592

Parsons, A. L., \& Lepkowska-White, E. (2010). Web site references in print advertising: An analysis of calls to action. Journal of Internet Commerce, 9(3-4), 151-163. https://doi.org/10.1080/15332861.2010.526487

Price, M., Handley, K., Millar, J., \& O'Donovan, B. (2010). Feedback: All that effort, but what is the effect? Assessment \& Evaluation in Higher Education, 35(3), 277-289. https://doi.org/10.1080/02602930903541007

R Core Team. (2019). R: A language and environment for statistical computing. Vienna, Austria: R Foundation for Statistical Computing. Retrieved from https://www.R-project.org/

Robin, X., Turck, N., Hainard, A., Tiberti, N., Lisacek, F., Sanchez, J.-C., \& Müller, M. (2011). pROC: an open-source package for $\mathrm{R}$ and $\mathrm{S}+$ to analyze and compare ROC curves. BMC Bioinformatics, 12(1), 77. https://doi.org/10.1186/1471-2105-12-77

Rodgers, J. L., \& Nicewander, W. A. (1988). Thirteen ways to look at the correlation coefficient. The American Statistician, 42(1), 59-66. https://doi.org/10.1080/00031305.1988.10475524

Rowe, A. D. (2017). Feelings about feedback: The role of emotions in assessment for learning. In D. Carless, S. M. Bridges, C. K. Y. Chan, \& R. Glofcheski (Eds.), Scaling up assessment for learning in higher education (pp. 159-172). Singapore: Springer Singapore. https://doi.org/10.1007/978-981-10-3045-1_11

Rowe, A. D., \& Wood, L. N. (2009). Student perceptions and preferences for feedback. Asian Social Science, 4(3), 78-88. https://doi.org/10.5539/ass.v4n3p78

Ryan, T., Gašević, D., \& Henderson, M. (2019). Identifying the impact of feedback over time and at scale: Opportunities for learning analytics. In M. Henderson, R. Ajjawi, D. Boud, \& E. Molloy (Eds.), The impact of feedback in higher education: Improving assessment outcomes for learners (pp. 207-223). Cham, Switzerland: Springer International Publishing. https://doi.org/10.1007/978-3-030-25112-3_12

Sahni, N. S., Wheeler, S. C., \& Chintagunta, P. (2018). Personalization in email marketing: The role of noninformative advertising content. Marketing Science, 37(2), 236-258. https://doi.org/10.1287/mksc.2017.1066

Senko, C., Hulleman, C. S., \& Harackiewicz, J. M. (2011). Achievement goal theory at the crossroads: Old controversies, current challenges, and new directions. Educational Psychologist, 46(1), $26-47$. https://doi.org/10.1080/00461520.2011.538646

Sharp, B. (2017). Marketing: Theory, evidence, practice. Oxford, UK: Oxford University Press.

Shute, V. J. (2008). Focus on formative feedback. Review of Educational Research, 78(1), 153-189. https://doi.org/10.3102/0034654307313795

Singh, G., Singh, H., \& Shriwastav, S. (2019). Improving email marketing campaign success rate using personalization. In A. K. Laha (Ed.), Advances in Analytics and Applications (pp. 77-83). Singapore: Springer Singapore. https://doi.org/10.1007/978-981-13-1208-3_8 
Sutton, P. (2012). Conceptualizing feedback literacy: Knowing, being, and acting. Innovations in Education and Teaching International, 49(1), 31-40. https://doi.org/10.1080/14703297.2012.647781

Szymanski, D. M., \& Hise, R. T. (2000). E-satisfaction: An initial examination. Journal of Retailing, 76(3), 309-322. https://doi.org/10.1016/S0022-4359(00)00035-X

Teasley, S. D. (2017). Student facing dashboards: One size fits all? Technology, Knowledge and Learning, 22(3), 377-384. https://doi.org/10.1007/s10758-017-9314-3

Tempelaar, D., Rienties, B., Mittelmeier, J., \& Nguyen, Q. (2018). Student profiling in a dispositional learning analytics application using formative assessment. Computers in Human Behavior, 78, 408-420. https://doi.org/10.1016/j.chb.2017.08.010

Turner, G., \& Gibbs, G. (2010). Are assessment environments gendered? An analysis of the learning responses of male and female students to different assessment environments. Assessment \& Evaluation in Higher Education, 35(6), 687-698. https://doi.org/10.1080/02602930902977723

Winne, P. H., \& Hadwin, A. F. (1998). Studying as self-regulated learning. In D. J. Hacker, J. Dunlosky, \& A. C. Graesser (Eds.), Metacognition in educational theory and practice (pp. 277-304). Mahwah, NJ, USA: Lawrence Erlbaum Associates Publishers. Retrieved from https://psycnet.apa.org/record/1998-07283-011

Winstone, N. E. (2019). Facilitating students' use of feedback: Capturing and tracking impact using digital tools. In M. Henderson, R. Ajjawi, D. Boud, \& E. Molloy (Eds.), The impact of feedback in higher education: Improving assessment outcomes for learners (pp. 225-242). Cham, Switzerland: Springer International Publishing. https://doi.org/10.1007/978-3-030-25112-3_13

Winstone, N. E., Mathlin, G., \& Nash, R. A. (2019). Building feedback literacy: Students' perceptions of the developing engagement with feedback toolkit. Frontiers in Education, 4, 1-11. https://doi.org/10.3389/feduc.2019.00039

Winstone, N. E., \& Nash, R. (2016). The "Developing Engagement with Feedback Toolkit (DEFT)": Integrating assessment literacy into course design (Tech. Rep.). York, UK: Higher Education Academy. Retrieved from https://www.heacademy.ac.uk/system/files/resources/ the_developing_engagement_with_feedback_toolkit_deft_0.pdf

Winstone, N. E., Nash, R. A., Parker, M., \& Rowntree, J. (2017). Supporting learners' agentic engagement with feedback: A systematic review and a taxonomy of recipience processes. Educational Psychologist, 52(1), 17-37. https://doi.org/10.1080/00461520.2016.1207538

Winstone, N. E., Nash, R. A., Rowntree, J., \& Parker, M. (2017). 'It'd be useful, but I wouldn't use it': Barriers to university students' feedback seeking and recipience. Studies in Higher Education, 42(11), 2026-2041. https://doi.org/10.1080/03075079.2015.1130032

Wisniewski, B., Zierer, K., \& Hattie, J. (2020). The power of feedback revisited: A meta-analysis of educational feedback research. Frontiers in Psychology, 10, 3087. https://doi.org/10.3389/fpsyg.2019.03087

Wong, B. T. M., \& Li, K. C. (2018). Learning analytics intervention: A review of case studies. In 2018 International Symposium on Educational Technology (ISET 2018), 31 July-2 August 2018, Osaka, Japan (pp. 178-182). New York: IEEE. https://doi.org/10.1109/ISET.2018.00047

Zhang, X. A., Kumar, V., \& Cosguner, K. (2017). Dynamically managing a profitable email marketing program. Journal of Marketing Research, 54(6), 851-866. https://doi.org/10.1509/jmr.16.0210 


\section{Appendices}

\section{Student Engagement with Feedback Messages}

Table 6. The bioscience course-Student engagement with feedback messages for different groups of students that showed significant differences in logistic regression models. Total Emails Sent corresponds to the number of feedback emails with CTAs sent to a particular student group. Similarly, Total CTA Clicks corresponds to the number of times students from this group clicked on CTA hyperlinks.

\begin{tabular}{|c|c|c|c|c|c|}
\hline \multirow[b]{2}{*}{ Outcome variable (Topic) } & \multicolumn{2}{|c|}{ Significant Predictor } & \multicolumn{3}{|c|}{ Engagement } \\
\hline & Variable & Level & Total Emails Sent & Total CTA Clicks & Opening Rate \\
\hline \multirow{2}{*}{ Week 3 feedback engaged } & Gender & Male & 75 & 31 & $41 \%$ \\
\hline & & Female & 143 & 82 & $57 \%$ \\
\hline \multirow{2}{*}{ Week 4 feedback engaged (Quiz 1) } & Week 3 feedback engaged & No & 105 & 3 & $3 \%$ \\
\hline & & Yes & 113 & 43 & $38 \%$ \\
\hline \multirow{2}{*}{ Week 5 feedback engaged (Quiz 1) } & Week 3 feedback engaged & No & 105 & 9 & $9 \%$ \\
\hline & & Yes & 113 & 30 & $27 \%$ \\
\hline \multirow[t]{2}{*}{ Week 6 feedback engaged (Quiz 1) } & Week 3 feedback engaged & No & 105 & 6 & $6 \%$ \\
\hline & & Yes & 113 & 23 & $20 \%$ \\
\hline \multirow[t]{2}{*}{ Week 7 feedback engaged (Quiz 1) } & English at home & Yes & 182 & 6 & $3 \%$ \\
\hline & & No & 36 & 4 & $11 \%$ \\
\hline \multirow{4}{*}{ Week 9 feedback engaged (Quiz 2) } & Gender & Male & 71 & 9 & $13 \%$ \\
\hline & & Female & 127 & 37 & $29 \%$ \\
\hline & Week 4 feedback engaged & No & 153 & 22 & $14 \%$ \\
\hline & & Yes & 45 & 24 & $53 \%$ \\
\hline \multirow{12}{*}{ Week 10 feedback engaged (Quiz 2) } & Mature & Yes & 32 & 10 & $31 \%$ \\
\hline & & No & 166 & 26 & $16 \%$ \\
\hline & Previous attainment & Secondary education & 103 & 21 & $20 \%$ \\
\hline & & Some college & 10 & 0 & $0 \%$ \\
\hline & Previous attainment & VET course & 64 & 12 & $19 \%$ \\
\hline & & Nothing & 21 & 3 & $14 \%$ \\
\hline & Week 5 feedback engaged & No & 160 & 23 & $14 \%$ \\
\hline & & Yes & 38 & 13 & $34 \%$ \\
\hline & Week 6 feedback engaged & No & 169 & 22 & $13 \%$ \\
\hline & & Yes & 29 & 14 & $48 \%$ \\
\hline & Week 9 feedback engaged & No & 152 & 18 & $12 \%$ \\
\hline & & Yes & 46 & 18 & $39 \%$ \\
\hline \multirow[t]{4}{*}{ Week 11 feedback engaged (Quiz 2) } & Week 6 feedback engaged & No & 169 & 9 & $5 \%$ \\
\hline & & Yes & 29 & 5 & $17 \%$ \\
\hline & Week 9 feedback engaged & No & 152 & 6 & $4 \%$ \\
\hline & & Yes & 46 & 8 & $17 \%$ \\
\hline
\end{tabular}

Notes: VET: Vocational Education and Training. 
Table 7. The marketing course-Student engagement with feedback messages for different groups of students that showed significant differences in logistic regression models. Total Emails Sent corresponds to the number of feedback emails with CTAs sent to a particular student group. Similarly, Total CTA Clicks corresponds to the number of times students from this group clicked on CTA hyperlinks.

\begin{tabular}{|c|c|c|c|c|c|}
\hline \multirow[b]{2}{*}{ Outcome Variable (Topic) } & \multicolumn{2}{|c|}{ Significant Predictor } & \multicolumn{3}{|c|}{ Engagement } \\
\hline & Variable & Level & Total Emails Sent & Total CTA Clicks & Opening Rate \\
\hline \multirow[t]{4}{*}{ Week 1 feedback engaged (Assignment 1 ) } & Previous attainment & Secondary education & 11 & 2 & $18 \%$ \\
\hline & & Some college & 33 & 11 & $33 \%$ \\
\hline & & VET course & 21 & 9 & $43 \%$ \\
\hline & & Nothing & 10 & 4 & $40 \%$ \\
\hline \multirow[t]{7}{*}{ Week 2 feedback engaged (Assignment 1 ) } & Program & Management & 11 & 5 & $45 \%$ \\
\hline & & Human Resources & 11 & 5 & $45 \%$ \\
\hline & & Marketing & 19 & 4 & $21 \%$ \\
\hline & & Accounting & 28 & 17 & $61 \%$ \\
\hline & & IT \& Communication & 7 & 2 & $29 \%$ \\
\hline & Week 1 feedback engaged & No & 50 & 17 & $34 \%$ \\
\hline & & Yes & 26 & 16 & $62 \%$ \\
\hline \multirow[t]{6}{*}{ Week 3 feedback engaged (Assignment 1) } & Attendance & Full-time & 40 & 9 & $22 \%$ \\
\hline & & Part-time & 38 & 13 & $34 \%$ \\
\hline & Gender & Male & 25 & 6 & $24 \%$ \\
\hline & & Female & 53 & 16 & $30 \%$ \\
\hline & Week 1 feedback engaged & No & 52 & 8 & $15 \%$ \\
\hline & & Yes & 26 & 14 & $54 \%$ \\
\hline \multirow[t]{2}{*}{ Week 4 feedback engaged (Assignment 2) } & Week 2 feedback engaged & No & 45 & 6 & $13 \%$ \\
\hline & & Yes & 33 & 16 & $48 \%$ \\
\hline \multirow[t]{4}{*}{ Week 5 feedback engaged (Assignment 2) } & Admission basis & Secondary education & 17 & 2 & $12 \%$ \\
\hline & & VET & 19 & 4 & $21 \%$ \\
\hline & & Some college & 19 & 7 & $37 \%$ \\
\hline & & Other & 23 & 4 & $17 \%$ \\
\hline
\end{tabular}

Notes: VET: Vocational Education and Training. 